\title{
Educação para a Paz e a Mediação de Conflitos: um Direito e um Instrumento para a Promoção da Cultura de Paz
}

\author{
Educación para la Paz y la Mediación de Conflictos: un Derecho y un \\ Instrumento para la Promoción de la Cultura de Paz \\ Education for Peace and the Mediation of Conflicts: a Right and an \\ Instrument for the Promotion for a Culture of Peace
}

\author{
Alexandre Zacaria Sebaje ${ }^{1}$ \\ Lúcio Jorge Hammes ${ }^{2}$ \\ Itamar Luís Hammes ${ }^{3}$
}

\begin{abstract}
Resumo
O presente estudo, centrado teoricamente na interface entre as áreas da Educação e do Direito, compreende uma investigação de abordagem qualitativa, cujo escopo abrange questões pertinentes à promoção da cultura de paz e à mediação de conflito no âmbito da escola. O lócus focal da investigação é uma escola de Ensino Médio de Pelotas pertencente à Rede Pública Estadual de Ensino do Estado do Rio Grande do Sul. O corpus analítico emerge de dados obtidos por meio de um questionário com perguntas abertas, destacando-se a Análise de Conteúdo como método precípuo de tratamento dos dados obtidos. O estudo teve como mote investigativo as seguintes indagações: (i) Você já ouviu falar a respeito de Cultura de Paz? O que você entende da mesma? (ii) O que você entende por conflito? (iii) O que você entende por mediação de conflito? No sentido de buscar respostas a tais questões, traçouse como objetivo averiguar a percepção da comunidade escolar no que se refere à cultura de paz e à mediação de conflitos. Os resultados obtidos indicam a necessidade de qualificar os envolvidos no processo de ensinoaprendizagem para a promoção da cultura de paz e mediação de conflitos dentro da escola. Sugere-se, assim, a inclusão de cursos de formação e capacitação de professores, a fim de inspirar novas e potentes discussões e construções de saberes.
\end{abstract}

Palavras-chave: conflito; cultura de paz; formação; mediação de conflito.

\section{Resumen}

El presente estudio, centrado teóricamente en la interfaz entre las áreas de la Educación y del Derecho, comprende una investigación de enfoque cualitativo, cuyo objetivo abarca cuestiones pertinentes a la promoción de la cultura de paz y a la mediación de conflicto en el ámbito de la escuela. El lócus focal de la investigación es una escuela de Enseñanza Media de Pelotas perteneciente a la Red Pública Estadual de Enseñanza del Estado de Rio Grande do Sul. El corpus analítico emerge de datos obtenidos por medio de un cuestionario con preguntas abiertas, destacándose el Análisis de Contenido como método basilar de tratamiento de los datos obtenidos. El estudio tuvo como mote investigativo las siguientes indagaciones: (i) ¿Has oído hablar acerca de Cultura de Paz? ¿Qué entiende de la misma? (ii) ¿Qué entiende por conflicto? (iii) ¿Qué entiende por mediación de conflicto? En el sentido de buscar respuestas a tales cuestiones, se trazó como objetivo averiguar la percepción de la comunidad escolar en lo que se refiere a la cultura de paz y a la mediación de conflictos. Los resultados obtenidos indican la necesidad de calificar los involucrados en el proceso de enseñanza-aprendizaje para la promoción de la cultura de paz y la mediación de conflictos dentro de la escuela. Se sugiere, así, la inclusión de cursos de formación y capacitación de profesores, a fin de inspirar nuevas y potentes discusiones y construcciones de saberes.

\footnotetext{
${ }^{1}$ Mestrando em Educação; Universidade Federal do Pampa - UNIPAMPA; Jaguarão, RS, Brasil; azsebaje@gmail.com.

${ }^{2}$ Doutor em Educação; Universidade Federal do Pampa - UNIPAMPA; Jaguarão, RS, Brasil; luciojh@ gmail.com.

${ }^{3}$ Doutor em Filosofia; Instituto Federal de Educação, Ciência e Tecnologia Sul-rio-grandense - IFSUL; Lajeado, RS, Brasil; itamarh57@gmail.com.
} 
Palabras clave: conflicto; cultura de paz; formación; mediación de conflicto.

\begin{abstract}
The present study, theoretically centered in the interface between the field of Education and Law, comprises a qualitative approach investigation, whose scope covers issues regarding the promotion of the culture of peace and the mediation of conflict in the school environment. The focul locus of the investigation is a High School in Pelotas belonging to the Public School Education of the State of Rio Grande do Sul. The analytical corpus arises from data obtained through an open-question questionnaire, highlighting the Content Analysis as its main method to deal with the obtained data. The study investigative motto had the following questions: (i) Have you ever heard about the Culture of Peace? What do you understand about it? (ii) What do you understand by conflict? (iii) What do you understand by conflict mediation? With the purpose of seeking answers for such questions, we aimed to check the perception of the school community concerning the culture of peace and the mediation of conflicts. The results obtained indicate the necessity of qualifying the ones involved in the teaching-learning process for the promotion of the culture of peace and mediation of conflicts inside the school. It is, thus, suggested the inclusion of training courses for teachers, in order to prompt new and meaningful discussions and construction of knowledge.
\end{abstract}

Keywords: conflict; culture of peace; training; mediation of conflict.

\title{
1. Introdução
}

Com a introdução dos incisos IX e X, pela Lei $n^{\circ} 13.663 / 18$, no Art. 12 da Lei de Diretrizes e Bases da Educação (BRASIL, 2018), os estabelecimentos de ensino passaram, também, a ter a incumbência de estabelecer ações destinadas a promover a cultura de paz e medidas de conscientização, de prevenção e combate a todos os tipos de violência.

Art. 1ㅇ O caput do art. 12 da Lei $\mathrm{n}^{\circ}$ 9.394, de 20 de dezembro de 1996, passa a vigorar acrescido dos seguintes incisos:

"Art. 12

(...)

IX - promover medidas de conscientização, de prevenção e de combate a todos os tipos de violência, especialmente a intimidação sistemática (bullying), no âmbito das escolas;

$\mathrm{X}$ - estabelecer ações destinadas a promover a cultura de paz nas escolas. ”

Tendo presente esta nova base normativa, buscamos investigar até que ponto os membros que compõem a comunidade escolar, ou seja, direção, professores, funcionários e alunos são detentores do conhecimento em relação ao exposto nos dispositivos acrescentados ao artigo acima.

Nesse contexto, torna-se relevante ter um mínimo de conhecimento dos conceitos mencionados nos incisos em questão para que se possa, assim, realmente pôr em prática tais ações.

Frente a este novo contexto surge a necessidade de se estar atento às práticas desenvolvidas dentro do ambiente escolar e observar como elas se têm configurado, ou seja, buscar compreender os novos modos de composição das interações entre os sujeitos inseridos 
nessas atividades. Dessa forma, a presente pesquisa tem como objetivo averiguar a percepção da comunidade escolar no que se refere à cultura de paz e à mediação de conflitos.

Após a introdução, o artigo traz uma delimitação metodológica com a fundamentação dos caminhos da pesquisa que serão tratados com a perspectiva da Análise de Conteúdo para depois trazer a discussão e os resultados da mesma. Por fim, o artigo traz as considerações finais e as referências utilizadas.

\section{Metodologia}

A população do estudo em questão são oito professores, duas funcionárias, 50 alunos e equipe diretiva da escola. O educandário, de ensino médio, pertence à Rede Pública Estadual de Ensino do Estado do Rio Grande do Sul e está localizado na região de Pelotas.

O presente estudo tem uma abordagem metodológica qualitativa a partir de um questionário com perguntas abertas a respeito da cultura de paz e mediação de conflitos. No intuito de contemplar os objetivos indicados, elegeu-se a referida abordagem para o desenvolvimento da presente pesquisa, a qual, segundo Minayo (1994).

(...) responde a questões muito particulares. Ela se preocupa, nas ciências sociais, com um nível de realidade que não pode ser quantificado. Ou seja, ela trabalha com o universo de significados, motivos, aspirações, crenças, valores e atitudes, o que corresponde a um espaço mais profundo das relações, dos processos e dos fenômenos que não podem ser reduzidos à operacionalização de variáveis. (MINAYO 1994, p. 21-22)

Segundo Gil (2008), o questionário pode ser definido como a técnica de investigação composta por um número mais ou menos elevado de questões apresentadas por escrito às pessoas, tendo por objetivo o conhecimento de opiniões, crenças, sentimentos, interesses, expectativas, situações e etc. $\mathrm{O}$ autor, ainda, diz que o questionário aberto é aquele que utiliza questões de respostas abertas e que, por sua vez, proporciona respostas de maior profundidade e com grande liberdade de expressão. Portanto, as respostas são mais fiéis no que se refere à opinião, pensamento do inquirido, além de ser mais vantajoso para o pesquisador, pois permite recolher variada informação sobre o tema em questão.

Nessa perspectiva, pode-se dizer que o presente estudo se caracteriza por ser uma pesquisa qualitativa, a qual se utilizou da Análise de Conteúdo como metodologia precípua de tratamento dos dados, por entender que esta se fundamenta como um guia para conduzir o estudo que aqui se investigou.

A metodologia Análise de Conteúdo, conforme Bardin (2011, p.44) consiste em "um conjunto de técnicas de análise das comunicações que utiliza procedimentos sistemáticos e 
objetivos de descrição do conteúdo das mensagens e que tem como finalidade a realização de inferências".

Olabuenaga e Ispizúa (1989, p.185) afirmam que a Análise de Conteúdo é uma técnica para ler e interpretar o conteúdo de toda classe de documentos, que analisados adequadamente nos abrem as portas ao conhecimento de aspectos e fenômenos da vida social de outro modo inacessível.

Portanto, o produto da análise de conteúdo pode constituir-se de qualquer material oriundo de comunicação verbal ou não-verbal, como questionários, cartas, cartazes, jornais, revistas, informes, livros, relatos autobiográficos, gravações, entrevistas e etc.

No entanto, os dados advindos dessas inúmeras fontes chegam ao pesquisador em estado bruto, necessitando, portanto, serem processados para, dessa maneira, facilitar o trabalho de compreensão, interpretação e inferência a que aspira a análise de conteúdo.

Cabe ressaltar que a análise de conteúdo, em sua vertente qualitativa, parte de uma série de pressupostos, os quais, no exame de um texto, servem de suporte para captar seu sentido simbólico. Dessa forma, é importante categorizar esses dados.

\section{Resultados e discussão}

Os resultados obtidos pelo trabalho deixaram evidente que uma grande parte dos participantes desconhece por inteiro o sentido da cultura de paz. Os demais apenas fazem menção ao conceito negativo da palavra paz, ou seja, desconsideram a concepção positiva desse vocábulo.

A paz deve ser entendida não somente em oposição à guerra, mas como prática da não violência na resolução dos conflitos, um exercício de diálogo e de uma postura democrática. Isto pressupõe dinâmica de cooperação planejada e a ação constante da busca e instauração da justiça.

A Organização das Nações Unidas (ONU) definiu cultura de paz na Declaração e Programa de Ação sobre uma Cultura de Paz, em 13 de setembro de 1999, da seguinte maneira:

Uma Cultura de Paz é um conjunto de valores, atitudes, tradições, comportamentos e estilos de vida baseados: No respeito à vida, no fim da violência e na promoção e prática da não-violência por meio da educação, do diálogo e da cooperação; No pleno respeito e na promoção de todos os direitos humanos e liberdades fundamentais; No compromisso com a solução pacífica dos conflitos; Nos esforços para satisfazer as necessidades de desenvolvimento e proteção do meio-ambiente para as gerações presentes e futuras; No respeito e fomento à igualdade de direitos e oportunidades de mulheres e homens; No respeito e fomento ao direito de todas as pessoas à liberdade de expressão, opinião e informação; $\mathrm{Na}$ adesão aos princípios de liberdade, justiça, democracia, tolerância, solidariedade, cooperação, pluralismo, diversidade cultural, 
diálogo e entendimento em todos os níveis da sociedade e entre as nações; e animados por uma atmosfera nacional e internacional que favoreça a paz (ONU, 1999, p.2-3).

Por sua vez Callado (2004, p.30) afirma que a Cultura de Paz pode ser pensada como filosofia de vida, como forma de regular os conflitos e como estratégia política para a transformação da realidade. Caracterizando-se pela busca coletiva de um modo de vida que contribua para a construção de um mundo mais justo, solidário e com paz. O autor aponta diferenças conceituais entre a Cultura de Paz e a Cultura Tradicional, conforme demonstrado no quadro abaixo:

Quadro 1 - Comparativo entre Cultura de Paz e Cultura Tradicional conforme Callado (2004).

\begin{tabular}{|l|l|}
\hline \multicolumn{1}{|c|}{ Cultura Tradicional (Paz Negativa) } & \multicolumn{1}{c|}{ Cultura de Paz (Paz Positiva) } \\
\hline $\begin{array}{l}\text { Paz definida como ausência de guerras e violência } \\
\text { direta. }\end{array}$ & $\begin{array}{l}\text { Paz definida como ausência de todo tipo de violência (direta ou } \\
\text { estrutural) e como presença de justiça social. }\end{array}$ \\
\hline $\begin{array}{l}\text { Paz limitada as relações nacionais e internacionais, cuja } \\
\text { manutenção depende dos Estados. }\end{array}$ & $\begin{array}{l}\text { Paz abrange todos os âmbitos da vida, incluídos o pessoal e o } \\
\text { interpessoal. A responsabilidade é de todos. }\end{array}$ \\
\hline $\begin{array}{l}\text { Paz como um fim, uma meta a que se tende e que nunca } \\
\text { se alcança plenamente. }\end{array}$ & Paz como processo contínuo e permanente. \\
\hline $\begin{array}{l}\text { O fim justifica os meios, podendo-se justificar a } \\
\text { violência para garantir a paz. }\end{array}$ & $\begin{array}{l}\text { Os meios não justificam os fins, assim como a violência não é } \\
\text { considerada um meio para se alcançar a paz. }\end{array}$ \\
\hline $\begin{array}{l}\text { Paz como ideal utópico e inalcançável, depende de } \\
\text { fatores externos a ela. }\end{array}$ & $\begin{array}{l}\text { Paz como processo contínuo e acessível por meio de ações de } \\
\text { cooperação, mútuo entendimento, dentre outras posturas que } \\
\text { assentam as bases das relações interpessoais e intergrupais. }\end{array}$ \\
\hline Conflito concebido como algo negativo. & $\begin{array}{l}\text { A forma de regular o conflito torna a situação positiva } \\
\text { (mediação/regulação) ou negativa (violência). }\end{array}$ \\
\hline Conflitos devem ser evitados. & $\begin{array}{l}\text { Conflitos devem ser manifestados e regulados, sem se recorrer à } \\
\text { violência (ação pacífica). }\end{array}$ \\
\hline
\end{tabular}

Fonte: Callado, 2004, p.28

Também, ficou evidente que a noção de conflitos e medição é bastante vaga para os participantes da pesquisa, visto que tratam o primeiro como sinônimo de briga e confusão e o segundo como um meio de interromper e evitar o conflito. De acordo com Chrispino e Chrispino (2002).

Conflito é toda opinião divergente ou maneira diferente de ver ou interpretar algum acontecimento. A partir disso, todos os que vivemos em sociedade temos a experiência do conflito. Desde os conflitos próprios da infância, passamos pelos conflitos pessoais da adolescência e, hoje, visitados pela maturidade, continuamos a conviver com o conflito intrapessoal (...) ou interpessoal. (CHRISPINO; CHRISPINO, 2002, p. 16)

O conflito é o nosso companheiro de jornada mais próximo. É parte integrante da vida e da atividade social. O conflito se origina da diferença de interesses, de desejos e aspirações. (CHRISPINO; CHRISPINO, 2002, p.30-31).

Como podemos constatar, os conflitos são inerentes à condição humana. A divergência de opiniões, dificuldade de comunicação e assertividade das pessoas são as possíveis causas que intensificam a ocorrência de conflitos, as quais podem surgir quando há a necessidade de escolha entre situações divergentes.

Ainda em relação ao conflito, Guimarães (2005) afirma: 
O conflito é um elemento conatural da vida pessoal; não é necessariamente negativo, dependendo do modo como é enfrentado, gerido e resolvido, seguramente causa sofrimento, mas pode ser ocasião de crescimento e mudança, pessoal e coletiva. Para isso é necessário reconhecer os conflitos e não removê-los, ou fazê-los emergir, quando são latentes, mas constituem um problema real ao menos para uma das partes. Também a paz não é ausência de conflitos, nem apenas ausência de guerra, mas ausência da violência em todas as suas formas (PACE e DINTORNI apud GUIMARÃES, 2005, p. 70).

No que tange a mediação de conflitos, Ortega (2002) diz que:

\begin{abstract}
A mediação é a intervenção, profissional ou profissionalizada, de um terceiro - um especialista - no conflito travado entre duas partes que não alcançam, por si mesmas, um acordo nos aspectos mínimos necessários para restaurarem uma comunicação, um diálogo que, é necessário para ambas (...) com o reconhecimento da responsabilidade individual de cada um no conflito e o acordo sobre como agir para eliminar a situação de crise com o menor custo de prejuízo psicológico, social ou moral para ambos os protagonistas e suas repercussões em relação a terceiros envolvidos. (p. 147)
\end{abstract}

Dessa forma, a mediação representa um mecanismo de resolução de conflitos. Segundo Sales (2007, p.23), a mediação é um procedimento consensual de solução de conflitos, por meio do qual uma terceira pessoal imparcial, escolhida ou aceita pelas partes, age no sentido de encorajar e facilitar a resolução de uma divergência.

Portanto, a mediação de conflitos dentro do ambiente escolar deve buscar a prevenção e a resolução de questões que já estão instaladas na escola e que acabam prejudicando os relacionamentos e a qualidade do processo de ensino-aprendizagem. Para tanto, o conflito deve ser visto como normal e até positivo, visto que permite transformação e crescimento.

Tendo em vista que ensinar é um processo que envolve orientação Piva Jr. (2013, p.7) afirma que "só pode orientar aquele que conhece, aquele que possui uma boa base teórica e comunicacional, aquele que consegue caminhar diante de tantas mudanças. " Dessa forma, torna-se imperioso capacitar professores para que possam trabalhar com a promoção da Cultura de Paz e com resoluções de conflito no âmbito escolar.

Com o questionário aberto foi possível levantar indicadores que se referem à Cultura de Paz, ao conflito e a Mediação de Conflitos e, principalmente, sobre o conhecimento/desconhecimento dos sujeitos participantes acerca deles. Sobre a pesquisa documental, Gil (2008) explica que:

Há dados que embora referentes a pessoas, são obtidos de maneira indireta, que tomam a forma de documentos, como livros, jornais, papéis oficiais, registros estatísticos, fotos, discos, filmes e vídeos, que são obtidos de forma indireta. Essas fontes documentais são capazes de proporcionar ao pesquisador dados em quantidade e qualidade suficiente para evitar a perda de tempo e o constrangimento que caracterizam muitas das pesquisas em que os dados são obtidos diretamente das pessoas. Sem contar que em muitos casos só se torna possível realizar uma investigação social por meio de documentos (p. 147). 
RELACult - Revista Latino-Americana de Estudos em Cultura e Sociedade

Revista Latinoamericana de Estudios en Cultura y Sociedad | Latin American Journal of Studies in Culture and Society V. 05, ed. especial, abr., 2019, artigo no 1102 | claec.org/relacult | e-ISSN: 2525-7870

De posse dos dados, passou-se a categorização das unidades de análise. Para a criação destas categorias foi necessário considerar alguns critérios, como: validade, pertinência e adequação aos objetivos. De acordo com Moraes (1999), a categorização é:

Um procedimento de agrupar dados considerando a parte comum existente entre eles. Classifica-se por semelhança ou analogia, segundo critérios previamente estabelecidos ou definidos no processo. Estes critérios podem ser semânticos, originando categorias temáticas. Podem ser sintáticos definindo-se categorias a partir de verbos, adjetivos, substantivos, etc. As categorias podem ainda ser constituídas a partir de critérios léxicos, com ênfase nas palavras e seus sentidos ou podem ser fundadas em critérios expressivos focalizando em problemas de linguagem. Cada conjunto de categorias, entretanto, deve fundamentar-se em apenas um destes critérios (p. 06).

Quadro 2 - Descrição quantitativa das ocorrências relacionadas a categoria "Cultura de Paz" e seus respectivos indicadores.

\begin{tabular}{|l|l|c|c|c|c|}
\hline $\begin{array}{l}\text { Categoria 1: } \\
\text { "Cultura de } \\
\text { Paz" }\end{array}$ & \multicolumn{1}{|c|}{ Indicadores } & $\begin{array}{c}\text { Direção } \\
(\mathbf{0 3})\end{array}$ & $\begin{array}{c}\text { Professores } \\
\mathbf{( 0 8 )}\end{array}$ & $\begin{array}{c}\text { Funcionárias } \\
\mathbf{( 0 2 )}\end{array}$ & $\begin{array}{c}\text { Alunos } \\
\mathbf{( 5 0 )}\end{array}$ \\
\hline Conhece & $\begin{array}{l}\text {-Presença de justiça social, solidariedade, } \\
\text { cooperação e respeito. } \\
\text {-Solução pacífica dos conflitos. }\end{array}$ & 01 & 02 & - & 03 \\
\hline Desconhece & -Uso do advérbio de negação & 01 & 05 & 02 & 37 \\
\hline $\begin{array}{l}\text { Conhece em } \\
\text { parte }\end{array}$ & -Evitar conflitos. & 01 & 01 & - & 10 \\
\hline TOTAL & & 03 & 08 & 02 & 50 \\
\hline
\end{tabular}

Fonte: Própria

O gráfico abaixo ajuda a visualizar melhor o resultado dos dados, demonstrando a percepção dos participantes em relação a categoria "Cultura de Paz": 


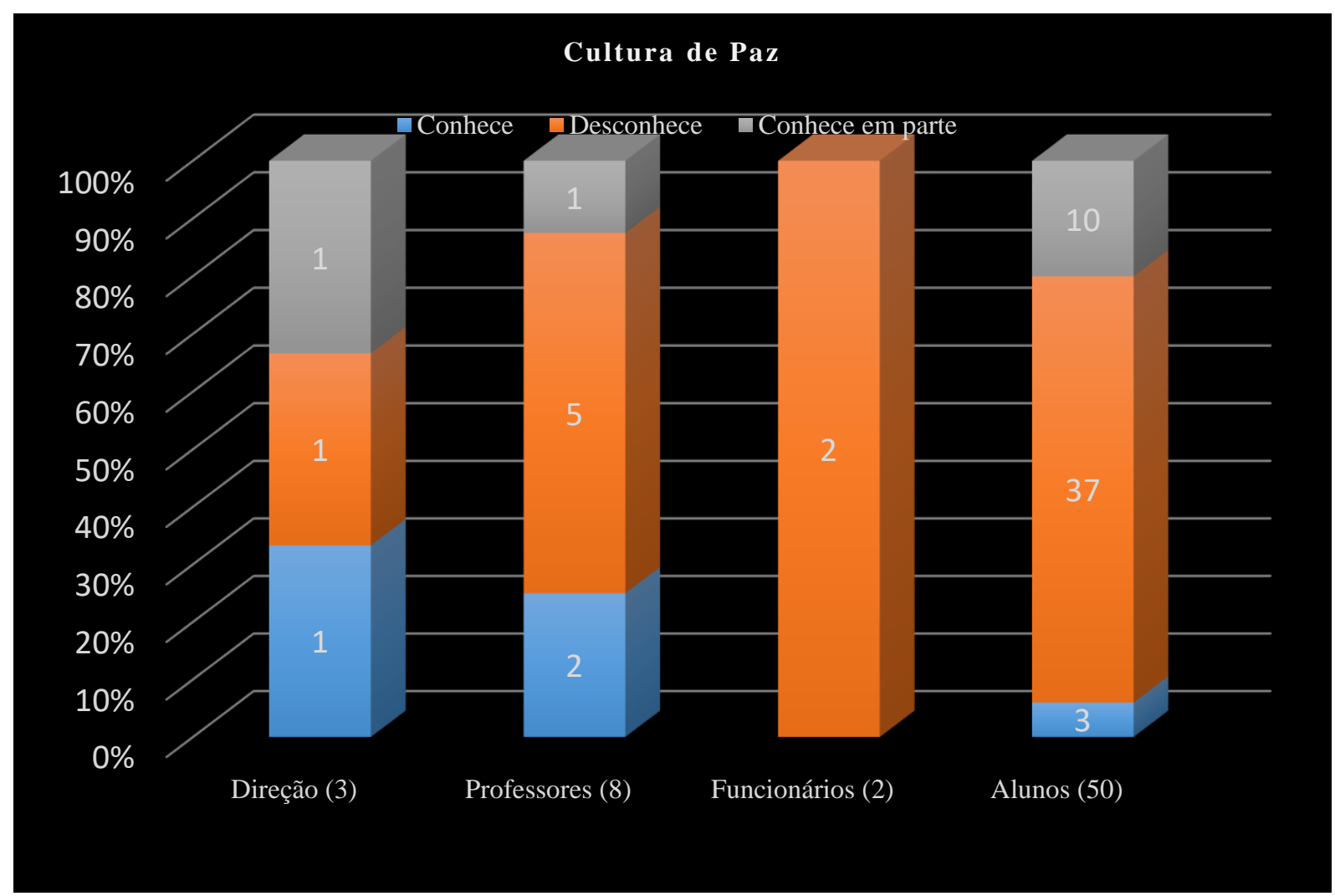

Gráfico 1: Cultura de Paz

Fonte: Própria

Conforme o gráfico acima percebe-se que $71 \%$ dos participantes da pesquisa desconhecem o significado de "cultura de paz".

Também, fica evidente que dos membros da comunidade escolar que trabalham diretamente com os alunos, ou seja, direção, professores e funcionários, somente 03, numa amostra de 13 sujeitos, demonstram conhecimento em relação a categoria acima. Ou seja, 77\% dos sujeitos não sabem o que é cultura de paz.

Quadro 3 - Descrição quantitativa das ocorrências relacionadas a categoria "Conflito" e seus respectivos indicadores.

\begin{tabular}{|l|l|c|c|c|c|}
\hline $\begin{array}{l}\text { Categoria 2: } \\
\text { "Conflito" }\end{array}$ & Indicadores & Direção & Professores & Funcionárias & Alunos \\
\hline Conhece & $\begin{array}{l}\text {-Inerente e natural. } \\
\text {-Positivo e negativo. }\end{array}$ & & 02 & 01 \\
\hline Desconhece & $\begin{array}{l}\text {-Uso do advérbio de } \\
\text { negação }\end{array}$ & & & & 05 \\
\hline $\begin{array}{l}\text { Conhece em } \\
\text { parte }\end{array}$ & $\begin{array}{l}\text {-Ocorrências de léxicos } \\
\text { como: briga, discórdia, } \\
\text { discussão e agressão. }\end{array}$ & 03 & 06 & 02 & 44 \\
\hline TOTAL & & 03 & 08 & 02 & 50 \\
\hline
\end{tabular}

Fonte: Própria 
RELACult - Revista Latino-Americana de Estudos em Cultura e Sociedade

Revista Latinoamericana de Estudios en Cultura y Sociedad | Latin American Journal of Studies in Culture and Society V. 05, ed. especial, abr., 2019, artigo n 1102 | claec.org/relacult | e-ISSN: 2525-7870

O gráfico abaixo manifesta de forma quantitativa a percepção dos participantes em relação a categoria "Conflito":

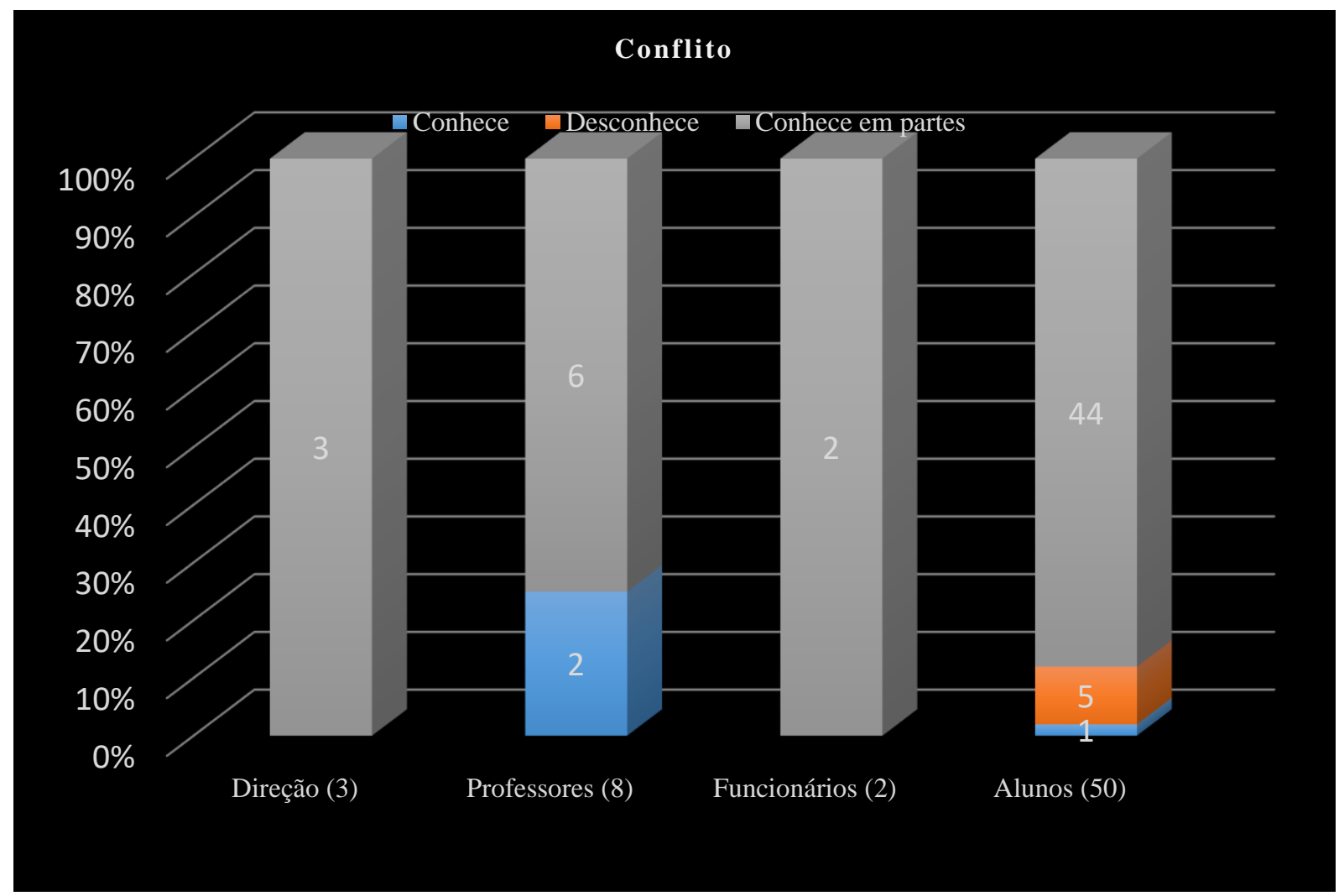

Gráfico 2: Conflito

Fonte: Própria

Em relação a categoria “conflito", somente 03 participantes, dentre eles 02 professores, num total de 63, conhecem o sentido do vocábulo. Com exceção de 05 sujeitos, que o desconhecem por inteiro, os demais (55) conhecem somente o aspecto negativo da palavra, ou seja, como sinônimo de briga, discórdia e agressão. Não sabem ou não percebem que conflito é algo natural e que pode ser positivo. Portanto, 95\% dos sujeitos desconhecem o significado, por inteiro, do léxico conflito.

Quadro 4 - Descrição quantitativa das ocorrências relacionadas a categoria "Mediação de Conflito" e seus respectivos indicadores.

\begin{tabular}{|c|c|c|c|c|c|}
\hline $\begin{array}{c}\text { Categoria 3 } \\
\text { "Mediação de } \\
\text { Conflito" }\end{array}$ & Indicadores & Direção & Professores & Funcionárias & Alunos \\
\hline
\end{tabular}


RELACult - Revista Latino-Americana de Estudos em Cultura e Sociedade

Revista Latinoamericana de Estudios en Cultura y Sociedad | Latin American Journal of Studies in Culture and Society V. 05, ed. especial, abr., 2019, artigo no 1102 | claec.org/relacult |e-ISSN: 2525-7870

\begin{tabular}{|c|c|c|c|c|c|}
\hline Conhece & $\begin{array}{l}\text {-Solução/resolução de } \\
\text { conflitos. } \\
\text {-Terceira pessoa facilita a } \\
\text { resolução. } \\
\text {-Imparcialidade. }\end{array}$ & 01 & 02 & & 02 \\
\hline Desconhece & $\begin{array}{l}\text {-Uso do advérbio de } \\
\text { negação. }\end{array}$ & 01 & 01 & 01 & 33 \\
\hline $\begin{array}{l}\text { Conhece em } \\
\text { parte }\end{array}$ & $\begin{array}{l}\text {-Solução/resolução de } \\
\text { conflitos. } \\
\text {-Uso do verbo "fazer, } \\
\text { interromper e impedir". }\end{array}$ & 01 & 05 & 01 & 15 \\
\hline TOTAL & & 03 & 08 & 02 & 50 \\
\hline
\end{tabular}

Fonte: Própria

O gráfico abaixo, de forma quantitativa, evidencia a percepção dos participantes em relação a categoria "Mediação de Conflito":

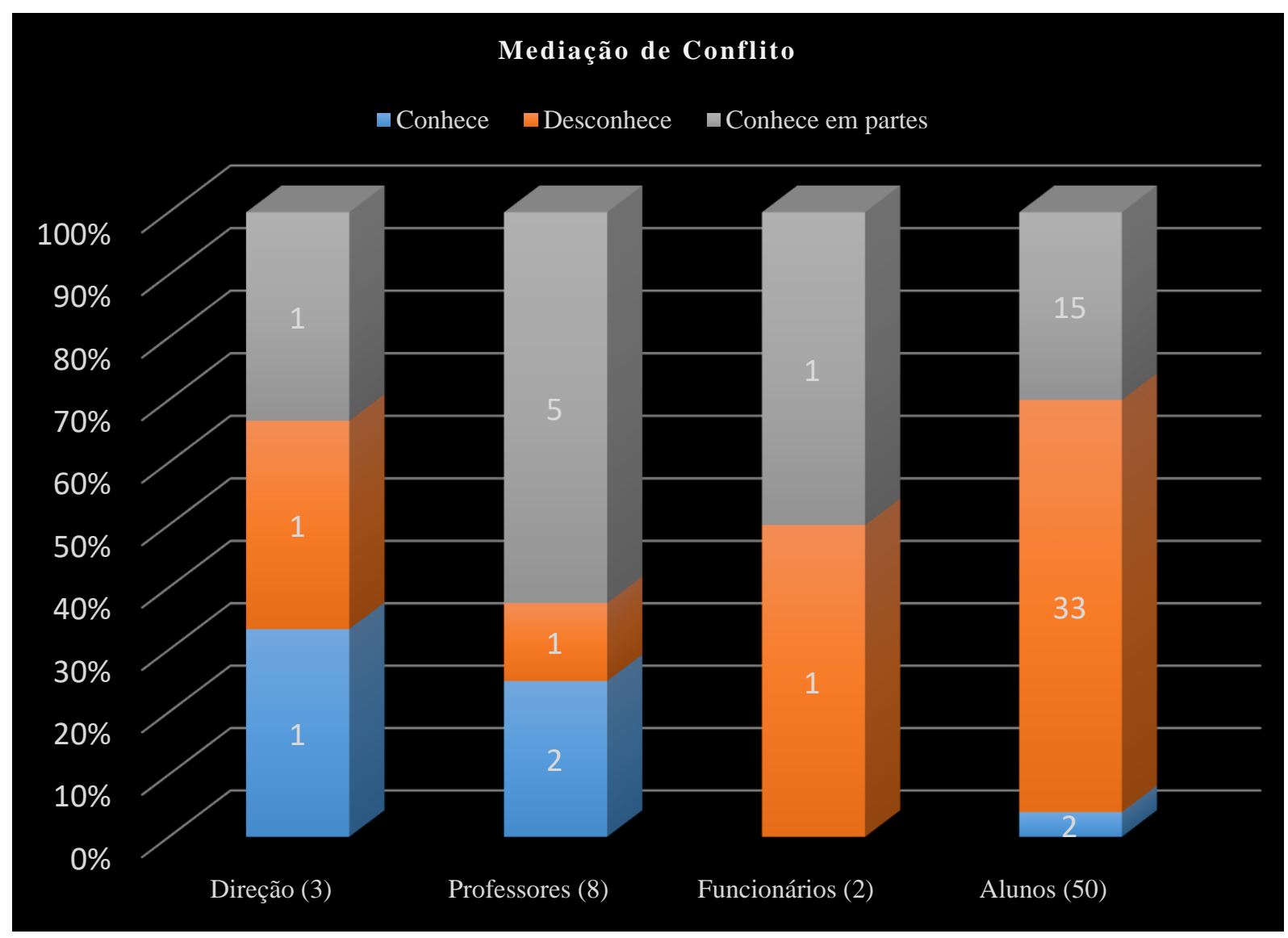

Gráfico 3: Mediação de Conflito

Fonte: Própria

Por fim, no que se refere à categoria "mediação de conflito", somente 05 participantes (01 membro da direção, 02 professores e 02 alunos) responderam que se trata de um meio de 
solução de conflitos e que se dá por intermédio de uma terceira pessoa que é imparcial e facilitadora na resolução. Dessa forma, fica evidente de que tanto a direção quanto os professores não têm uma percepção clara do que é mediação, visto que num universo de 11 participantes, 08 não conseguiram definir mediação, ou seja, aproximadamente $73 \%$ da amostra.

\section{Considerações finais}

No que concerne aos objetivos a presente investigação demonstra a importância e a necessidade de formar pessoas, ou seja, qualificar os evolvidos no processo de ensinoaprendizagem para a promoção da cultura de paz e mediação de conflitos dentro da escola. Ademais, dados emergentes inusitados foram identificados e sugerem a participação ativa frente à relevância de ampliar e aprofundar conhecimentos acerca do tema em questão. Sugerese a inclusão de cursos de formação e capacitação de professores, a fim de inspirar novas e potentes discussões e construções de saberes.

Os resultados, também, deixam evidente que é imperioso a implementação de medidas de compliance escolar, de forma a criar instruções internas aptas a nortear e orientar todos os membros da comunidade escolar com o claro objetivo de coibir a violência em todos os seus aspectos. De acordo com dados do $3^{\circ}$ Volume do Programa Internacional de Avaliação de Estudantes (Pisa) 2015, em cada dez estudantes um é vítima de bullying. Portanto, é dever imediato cumprir a determinação legal. É importante não esperar o problema acontecer. As condutas dos profissionais da educação devem ser preventivas e não apenas reativas. Ademais, conforme os dispositivos legais, os profissionais da educação podem responder pelo serviço defeituoso, por ação, omissão, negligência e imprudência tanto no que diz respeito ao Código de Defesa do Consumidor quanto na esfera civil e penal.

\section{Referências}

BARDIN L. Análise de conteúdo. SP: Edições 70, 2011.

BRASIL. Lei $n^{o}$ 13.663, de 14 de maio de 2018. Disponível em: <http://www.planalto.gov.br/ccivil_03/_ato2015-2018/2018/lei/L13663.htm>. Acesso em: 19 de set. 2018.

CALLADO C. V. Educação para a Paz: promovendo valores humanos na escola através da educação física e dos jogos cooperativos. Santos/SP: Editora Projeto Cooperação Ltda, 2004.

CHRISPINO, A.; CHRISPINO, R. S. P. Políticas Educacionais de redução da violência: mediação do conflito escolar. São Paulo: Editora Biruta, 2002. 
GIL, Antônio Carlos. Métodos e Técnicas de Pesquisa Social. 6. ed. São Paulo: Atlas, 2008.

GUIMARÃES, Marcelo Rezende. Educação para a paz: sentidos e dilemas. Caxias do Sul, RS: Educs, 2005.

MINAYO, Maria Cecília de Souza. Pesquisa Social: teoria, método e criatividade. Petrópolis: Vozes, 1994.

MORAES, Roque. Análise de conteúdo. Revista Educação, Porto Alegre, v. 22, n. 37, p. 7-32, 1999.

<file://C:/Users/stic\%202/Desktop/RoqueMoraes_Analise\%20de\%20conteudo-1999.pdf>.

Acesso em: 20/08/2018.

OLABUENAGA, J.I. R.; ISPIZUA, M.A. La descodificacion de la vida cotidiana: metodos de investigacion cualitativa. Bilbao, Universidad de deusto, 1989.

ONU, Declaração e Plano de Ação Sobre uma Cultura de Paz. Resolução A/ RES/ 53/ 243, de 06 de outubro de 1999 da Assembleia Geral da Organização das Nações Unidas. Disponível em: http://www.comitepaz.org.br. Acesso em: 15 set. 2018.

ORTEGA, Rosário et al. Estratégias educativas para prevenção das violências. Tradução de Joaquim Ozório - Brasília: UNESCO, UCB, 2002.

PISA 2015 RESULTS (VOLUME III): STUDENTS' WELL-.https://www.oecdilibrary.org/education/pisa-2015-results-volume-iii_9789264273856-em acessado em 10 de set de 2018.

PIVA Júnior, Dilermano. Sala de Aula Digital: uma introdução à cultura digital para educadores. $1^{a}$ ed. São Paulo: Saraiva, 2013.

SALES, Lília Maia de Morais. Mediação de conflitos: família, escola e comunidade. Florianópolis: Conceito Editorial, 2007. 